\title{
Kliniğimizde ektopik gebelik nedeniyle tedavi edilen 64 olgunun retrospektif analizi
}

\author{
Retrospective analysis of 64 patients treated with ectopic pregnancy in our clinic \\ Ünal Turkay, Hasan Terzi, Arzu Yavuz*, Ahmet Kale \\ Kadın Hastalıkları ve Doğum Kliniği (Dr. Ü. Turkay, Dr. H. Terzi, Dr. A. Yavuz, Dr. A. Kale), \\ Kocaeli Derince Eğitim ve Araştırma Hastanesi, TR-41900 Kocaeli
}

\begin{abstract}
Özet
Amaç. Kliniğimizde ektopik gebelik tanısı alan hastaların tanı yöntemleri ve tedavi seçenekleri açısından retrospektif analizlerini yapmak. Yöntem. Ocak 2007-Aralık 2012 tarihleri arasında kliniğimizde ektopik gebelik tanısı alan ve tedavisi yapılan 64 olgu demografik özelliklerine, tanısal yöntemlerine ve tedavi seçeneklerine göre değerlendirildi. Bulgular. Hastalarımızın yaş ortalaması 31,3’tür. Risk faktörleri sıklık sırasına göre abdominopelvik cerrahi öyküsü (\%17), rahim içi araç (RİA) öyküsü $(\% 6,2)$, geçirilmiş ektopik gebelik öyküsü $(\% 6,2)$, pelvik inflamatuar hastalık öyküsü (PID) (\% 2) idi. Hastaların kliniğimize en sık başvuru şikayeti pelvik ağrı ve amenore $(\% 54,6)$ olup bunu takiben sırası ile, vajinal kanama ile birlikte pelvik ağrı $(\% 40.6)$ ve sadece vajinal kanamaydı $(\% 4,6)$. Başvuru esnasında olguların ortalama insan koryonik gonadotropin $(\beta-\mathrm{HCG})$ değeri $3496 \mathrm{mLU} / \mathrm{mL}$ olarak tespit edildi. Olguların \%96,8'ine yapılan transvajinal ultrasonda (TVUSG) ektopik gebelik bulguları mevcuttu. Bütün hastalar cerrahi olarak tedavi edildi. Operasyonların \%53'ü laparotomi ile, \%47'si laparoskopi ile yapıldı. Yapılan ameliyatlar salpenjektomi (\%62,5), salpingostomi $(\% 29,7)$, parsiyel ooferektomi $(\% 3,1)$ ve ooferektomi $(\% 1,6)$ idi. Sonuç. Ektopik gebelikler, hastanın ilerideki hayatta fertilite yeteneğini bozması hatta maternal mortaliteye yol açabilmesi nedeniyle önemli bir sağlık sorunudur. Sunduğumuz çalışma, ektopik gebeliğin tanısında anamnez, $\beta$-HCG ve transvajinal ultrasonun önemini göstermektedir. Tedavide ise cerrahi özellikle salpenjektomi; tubal hasarlı ve hemodinamik olarak instabil olgularda en sık tercih edilen yöntem olarak öne çıkmaktadır.
\end{abstract}

Anahtar sözcükler: Ektopik gebelik, risk faktörleri, teşhis, tedavi

\begin{abstract}
Aim. The aim of this study was to analyze retrospectively diagnosting modalities and treatment options of ectopic pregnancies in our clinic. Method. Sixty-four cases who were treated ectopic pregnancy in our clinic between January 2007-December 2012 have been evaluated retrospectively for demographic features, diagnosting modalities and treatment approaches. Results. The avarage age of the patients were 31.3 years. The risk factors in the order of frequencies were previous abdominopelvic surgery (17\%), the use of intrauterine device $(6.2 \%)$, previous ectopic pregnancies $(6.2 \%)$ and previous pelvic inflammatory disease $(2 \%)$. The most common complaint on admission were pelvic pain and amenorea (54.6\%) and following that in the order of frequencies were vaginal bleeding with pain $(40.6 \%)$ and only vaginal bleeding $(4.6 \%)$. The serum mean $\beta$ HCG level of the patients on admission to our clinic was $3496 \mathrm{mLU} / \mathrm{mL}$. Transvaginal ultrasonographic findings of ectopic pregnancy were seen $96.8 \%$ of cases. All of the patients were surgically treated in our series. Fifty-three percent of patients were treated by laparotomy, $48 \%$ were treated with laparoscopy.Surgical procedures were salpingectomy $(62.5 \%)$, salpingostomy (29.7\%), partial oopherectomy (3.1\%) and oopherectomy(1.6\%). Conclusion. Ectopic pregnancies are important health problems since they may interfere with fertility capability of the patient in her future life and may even cause maternal mortality. History, serum $\beta$-HCG level and TVUSG are important diagnosting tools. Surgery especially salpingectomy is still the most frequently performed treatment option in cases with tubal damage and hemodinamically instable patients.
\end{abstract}

Keywords: Ectopic pregnancy, risk factors, diagnosis, treatment 


\section{*İletişim adresi:}

Dr. Arzu Yavuz, Kadın Hastalıkları ve Doğum Kliniği, Kocaeli Derince Eğitim ve Araştırma Hastanesi TR-41900 Kocaeli. E-posta: aslan_arzu81@mynet.com

\section{Giriş}

Ektopik gebelik; fertilize ovumun endometriyal kavite dışında implantasyonu olarak tanımlanır. Tüm gebeliklerin yaklaşık \%1,3-2'si ektopiktir [1]. Sanayileşmiş ülkelerde, gebeliğin ilk üç ayı içerisinde görülen anne ölümlerinin en önemli nedeni ektopik gebeliklerdir [2, 3]. Rüptüre ektopik gebelikler tüm maternal ölümlerin \%10-15'inden sorumludur [4]. Son y1llarda pelvik enfeksiyonların özellikle cinsel yolla bulaşan hastalıkların artışı ile ektopik gebelik insidansında artış olmasına rağmen, buna bağlı ölüm oranları azalmıştır. Bunun nedeni, $\beta$-HCG değerlerinin ve transvajinal ultrasonografinin yaygın olarak kullanılması ile ektopik gebeliklerin hayatı tehdit edecek olaylara yol açmadan erken teşhis edilmesidir [5]. Ektopik gebelik patogenezinde birçok mekanizma ortaya atılmış olmakla birlikte, fallop tüplerinde parsiyel obstrüksiyon varlığı ve siliyer hareketlerin bozulması bunların en önemlileridir. Bu duruma neden olabilecek risk faktörleri arasında, geçirilmiş PID, rahim içi araç kullanımı, tubal cerrahi öyküsü, geçirilmiş laparotomiler, infertilite öyküsü ve endometriyozis sayılabilir (6).Risk faktörlerinin erken gebeliği olan asemptomatik hasta grubunda taranması ile her ne kadar erken tanı imkanı olursa da ektopik gebelik tanısı koyulan hastaların yarısından fazlası hiçbir risk faktörüne sahip değildir [7, 8]. Ektopik gebeliğin klasik semptomları, adet gecikmesi, vajinal kanama ve pelvik ağrıdır. Ektopik gebeliğin fizik bulguları tubal rüptürün olup olmamasına göre değişkenlik gösterir. Rüptür olan hastalarda intraperitoneal kanamaya bağlı olarak karın ağrısı, hassasiyet ve rebound gibi muayene bulguları izlenebilirken, şoka kadar gidebilen hemodinamik bozukluk da izlenebilir. Tubal rüptürü olmayan hastalarda ise pelvik ağrıya değişen miktarlarda vajinal kanama eşlik edebilir. Ektopik gebelikte tedavi seçenekleri arasında, bekleme tedavisi, medikal tedavi ve cerrahi tedavi sayılabilir. Hastaların hemodinamik durumu, yaşı, gelecekteki fertilite isteği, serum $\beta$-HCG düzeyi, TVUSG bulguları ve tubal hasarına göre yukarıdaki tedavi seçeneklerinden biri seçilir. Cerrahi tedavi alternatifleri laparotomiden laparoskopiye kadar kendi içerisinde değişiklik gösterir. Yapılan çalışmalarda laparoskopinin laparotomiye göre birçok alanda üstünlügü gösterilmiştir [9, 10]. Batına giriş şeklinden bağımsız olarak cerrahi tedavide tercih edilmesi önerilen yöntem tuba koruyucu yöntem olan salpingostomi iken, salpenjektomi kontrol edilemeyen kanama, ağır tubal hasarlanma ve $5 \mathrm{~cm}$ 'den büyük gebelik kesesi olan olgulara saklanmalıdır [11]. $\mathrm{Bu}$ çalışmanın amacı, kliniğimizde beş yıllık sürede ektopik gebelik tanısı ile yatıp tedavi edilen hastaların tanı ve tedavi yaklaşımları açısından irdelenmesidir.

\section{Gereç ve yöntem}

Kocaeli Derince Eğitim ve Araştırma Hastanesi Kadın Hastalıkları ve Doğum kliniğinde Ocak 2007-Aralik 2012 tarihleri arasında ektopik gebelik tanısı alan ve tedavi edilen toplam 64 olgu retrospektif olarak incelendi. Olguların yaş, gebelik, doğum, düşük ve küretaj sayısı, korunma yöntemi, geçirilmiş ektopik gebelik, tubal sterilizasyon öyküsü, başvuru sırasındaki $\beta$-HCG değeri, ultrasonografik bulguları ve tedavi şekli hasta dosyaları ve ameliyat raporlarından incelendi. Tanımlayıcı veriler ortalama \pm standart sapma, ortanca ve oran olarak sunuldu. Gruplar arasındaki verilerin ortalamalarını karşılaştırmak için non-parametrik Mann-Whitney $U$ testi kullanıldı; $p<0,05$ anlamlı olarak kabul edildi. Veriler SPSS 11.0 paket programı (SPSS Inc., Chicago, USA) kullanılarak analiz edildi.

\section{Bulgular}

Retrospektif olarak değerlendirilen toplam 64 vakanın yaş aralığı 17-47 yaş olup, ortalaması 31.3 saptandı. Hastaların \%67, 1'i 30 yaşın üzerinde, \%32,9'u 30 yaş ve altında 
idi. Ektopik gebelik olgularının mevsimsel dağılımı incelendiğinde \%35,9 oranı ile en sık sonbahar aylarında görüldüğü bulunmuşstur. Hastaların hikayeleri, obstetrik özellikler ve olası predispozan faktörler açısından incelendiğinde \%71,8'inin bir veya daha fazla doğum yaptığı, \%28,1'inin bir ya da daha fazla spontan düşük yaptığı görüldü. Risk faktörleri yönünden sıklık sırasına göre geçirilmiş abdomino-pelvik cerrahi öyküsü \%17,1 rahim içi araç (RİA) öyküsü \%6,2; ektopik gebelik öyküsü \%6,2 ve geçirilmiş pelvik inflamatuar hastalık öyküsü $\% 2$, bilateral tüp ligasyonu öyküsü $\% 1,5$ bulunmuştur. Hastaların ilk başvuru nedenleri incelendiğinde en sık nedenin pelvik ağrı ve amenore olduğu saptanmıştır $(\% 54,6)$. Diğer başvuru nedenleri ise pelvik ağrı ve vajinal kanama $\% 40,6$, sadece vajinal kanama ise \%4,6'dır. Preoperatif dönemde hastaların \%96,8'inde ektopik gebeliği destekleyen TVUSG bulguları (adneksiyal kitle, hemoperitoneum , ekstrauterinyerleşimli fetal kardiak aktivite pozitif gebelik kesesi ) saptanmıştır. İki olguda ise ultrasonografiile ektopik gebeliğe spesifik bir bulguya rastlanılmamıştır. İlk başvuruda medyan $\beta$-HCG değeri $1736 \mathrm{mLU} / \mathrm{mL}$, ortalama $\beta$-HCG değeri ise 3496 $\mathrm{mLU} / \mathrm{mL}$ idi. Başvuru anında 10 olguda $(\% 15,6)$ hemodinamik instabilite mevcuttu. Elli dört olgunun $(\% 84,3)$ ise vital bulguları stabildi. Başvuru esnasında olguların \%21,8'inde kan ürünleri transfüzyonu ihtiyacı mevcuttu.

Tablo 1. Olguların demografik özelliklerine, $\beta$-HCG değerlerine, semptomlarına, risk faktörlerine ve TVUSG bulgularına göre dağılımları.

\begin{tabular}{|c|c|c|}
\hline & Sayı (n) & Oran (\%) \\
\hline \multicolumn{3}{|l|}{ Yașlar } \\
\hline 25 yaş altı & 11 & 17,1 \\
\hline $26-30$ yaş & 20 & 31,2 \\
\hline $31-35$ yaş & 25 & 39,0 \\
\hline 35 yaş üstü & 18 & 28,1 \\
\hline \multicolumn{3}{|l|}{ Mevsimler } \\
\hline Sonbahar & 23 & 35,9 \\
\hline Yaz & 16 & 25 \\
\hline İlkbahar & 13 & 20,3 \\
\hline $\mathrm{K}_{1}$ ş & 12 & 18,8 \\
\hline \multicolumn{3}{|l|}{$\beta$-HCG değerleri (mLU/mL) } \\
\hline $5-1500$ & 34 & 53,1 \\
\hline $1500-6000$ & 22 & 34,4 \\
\hline$>6000$ & 8 & 12,5 \\
\hline \multicolumn{3}{|l|}{ Başvuru şikayetleri } \\
\hline Pelvik ağrı & 61 & 95,3 \\
\hline Pelvik ağrı ve amenore & 35 & 54 \\
\hline Pelvik ağrı ve vajinal kanama & 26 & 40,6 \\
\hline Yalnızca vajinal kanama & 4 & 4,6 \\
\hline \multicolumn{3}{|l|}{ Risk faktörleri } \\
\hline \multicolumn{3}{|l|}{ Abdominopelvik cerrahi öyküsü } \\
\hline \multicolumn{3}{|l|}{ RİA öyküsü } \\
\hline \multicolumn{3}{|l|}{ Ektopik gebelik öyküsü } \\
\hline \multicolumn{3}{|l|}{ PID öyküsü } \\
\hline \multicolumn{3}{|l|}{ Tüp ligasyonu öyküsü } \\
\hline \multicolumn{3}{|l|}{ TVUSG bulguları } \\
\hline Ektopik gebelik bulguları & 62 & 96,8 \\
\hline Normal TVUSG bulguları & 2 & 3,2 \\
\hline
\end{tabular}

Hastaların tümüne cerrahi tedavi uygulandı. Operasyon sırasında görülen ektopik gebelik yerleşim yerlerinin dağılımına baktığımızda, \%84,3 olguda ektopik gebeliğin ampuller bölgede oluştuğu tespit edilmiştir. İstmus ve fimbriya bölge yerleşimleri ise sirasiyla $\% 7,8$ ve $\% 1,5$ olarak saptanmıştır. İki hastada ise overyan gebelik saptanmıştır. Otuzdört $(\% 53,1)$ hastaya laparotomi, $30(\% 46,9)$ hastaya ise laparoskopi yapıldı. Batına giriş tekniğinden bağımsız tercih edilen tedavi seçenekleri sırasıyla salpenjektomi $(\% 62,5)$, salpingostomi $(\% 29,7)$, parsiyel ooferektomi $(\% 3,1)$ ve ooferektomidir $(\% 1,6)$. İki $(\% 3,1)$ 
hastada ise tubal abort olduğu görülmüştür. Salpenjektomi uygulanan olguların tümünde tubal rüptür olduğu ameliyat notlarından saptanmıştır. Salpenjektomi ve salpingostomi uygulanan hastaların $\beta$-HCG değerleri karşılaştırıldığında aralarında anlamlı farklılık saptanmamıştır. Laparotomi yapılan hastalarda salpenjektominin, laparoskopi yapılan hastalara göre daha çok uygulandığı $(\% 70,5$ vs \%53,3) görülmüştür. Ancak aradaki fark istatiksel olarak anlamlı bulunmamıştır.

Tablo 2. Ektopik gebeliklerin yerleşim yerlerine, operasyonun şekline, uygulanan cerrahi yönteme ve hemodinamik durumlarına göre dağılımı.

\begin{tabular}{lll}
\hline & Sayı (n) & Oran (\%) \\
\hline Yerleşim yerleri & & \\
\hline Ampulla & 54 & 84,3 \\
Fimbriya & 5 & 7,8 \\
İstmus & 1 & 1,5 \\
Over & 2 & 3,1 \\
\hline Operasyon tipi & & \\
\hline Laparotomi & 34 & 53,1 \\
Laparoskopi & 30 & 46,9 \\
\hline Cerrahi yöntem & & \\
\hline Salpenjektomi & 40 & 62,5 \\
Salpingostomi & 19 & 29,7 \\
Parsiyel ooferektomi & 2 & 3,1 \\
Ooferektomi & 1 & 1,6 \\
Tubal abort & 2 & 3,1 \\
\hline Hemodinamik instabilite & 10 & 15,6 \\
\hline Kan transfüzyonu & 14 & 21,8 \\
\hline
\end{tabular}

Tablo 3. Uygulanan operasyona göre değerlendirmeler.

\begin{tabular}{|c|c|c|c|c|c|}
\hline \multirow[b]{4}{*}{$\beta$-HCG } & \multicolumn{4}{|c|}{ Operasyon } & \multirow[t]{3}{*}{${ }^{\mathrm{a}} \mathbf{p}$} \\
\hline & \multicolumn{2}{|c|}{ Salpenjektomi } & \multicolumn{2}{|c|}{ Salpingostomi } & \\
\hline & $n$ & Ort \pm SD & $\mathbf{n}$ & Ort \pm SD & \\
\hline & 40 & $1117,89 \pm 5,73$ & 19 & $1222,36 \pm 3,79$ & 0,855 \\
\hline & & n (\%) & & n (\%) & ${ }^{b} \mathbf{p}$ \\
\hline \multicolumn{6}{|c|}{ Operasyon tipi } \\
\hline Laparotomi & & $\begin{array}{l}24(\% 60,0) \\
16(\% 40,0)\end{array}$ & & $\begin{array}{l}8(\% 42,1) \\
11(\% 57,9)\end{array}$ & $\mathbf{0 , 3 1 3}$ \\
\hline
\end{tabular}

${ }^{a}$ Student $t$ test ${ }^{b}$ Yates continuity correction $\beta$-HCG için logaritmik dönüșüm uygulanmıştır.

\section{Tartışma}

Ektopik gebelik reprodüktif çağdaki cinsel aktif kadınlarda ortaya çıkabilen ve sonuçları itibarı ile ciddi bir hastalıktır. Genellikle 25-34 yaşları arasında görülür. Ektopik gebelik oranı 30 yaşından sonra giderek artmaya başlar ve özellikle de 35 yaşından sonra bu artış hızlanır [12]. Storeide ve ark. [13] 35 yaşın üzerindeki kadınlarda ektopik gebelik oluşma riskinin, 15-29 yaş grubundakilere göre 8 kat daha fazla olduğunu bildirmişlerdir ve bunu da yaşla beraber artan risk faktörlerine bağlamışlardır. Bizim olgularımız 17-47 yaşları arasında yer almaktadır ve ortalama görülme yaşı 31,3 olarak tespit edilmiştir. Hastalarımızın \%67,1'inin ise 30 yaşın üzerinde olduğu görülmektedir. Geçirilmiş abdominopelvik cerrahi öyküsü olan hastalarda özellikle tubal cerrahiler, tubal lümende destrüksiyona neden olarak ektopik gebelik için önemli risk faktörü oluşturmaktadır [14]. Yapılan bir çalışmada ektopik gebelik vakalarının \%19'unda pelvik operasyon öyküsü bidirilmiştir [15]. Çalışmamızda, vakaların \%17,1'inde saptanan geçirilmiş abdominopelvik cerrahi öyküsü literatür ile uyumludur. Rahim içi araç (RİA) kullanımı, enfeksiyona yatkınlık oluşturması nedeniyle ektopik gebelik açısından önemli bir risk faktörüdür [16]. Gebelik testi pozitif olan ve RİA kullanan bir kadının gebeliğinin, aksi ispat edilinceye kadar ektopik gebelik olarak kabul edilmesi önerilmektedir [17]. Çalı̧̧ma 
grubumuzda \%6,2 oranındaki RİA kullanım öyküsü, literatür verilerine paralel olarak RİA kullanımının ektopik gebelik gelişiminde önemli bir risk faktörü olabileceği fikrini desteklemektedir [18, 19]. Geçirilmiş ektopik gebelik öyküsü olanlarda, tekrarlama riski artmıştır [20, 21]. Ektopik gebelik nedeniyle uygulanan cerrahi yaklaşım özellikle salpingostomi ise, sonrasında gelişebilecek tubal hasar buna neden olabilir [22]. Çalışmamızda hastaların \%6,2'inde en az bir kez geçirilmiş ektopik gebelik hikayesi bulunmaktaydı. Pelvik inflamatuvar hastalık sonrasında ektopik gebelik riski 2-6 kat artmaktadır [17]. Çalışmamızda \%3,1 gibi literatürden daha düşük bir oranda PID öyküsü saptadık. Bu sonucun, hasta dosya kayıtlarındaki veya hastaların verdikleri anamnezlerdeki eksikliklerden kaynaklanabileceğini düşünmekteyiz.

Ektopik gebeliklerin \%98 yerleşim yeri fallop tüpleridir. İmplantasyon lokalizasyonlarına göre dağılımları ise \%70 ampuller, \%12 istmik, \%11,1 fimbrial, \%3,2 ovaryan, \%2,4 interstisiyel ve $\% 1,3$ abdominal olabilir $[19,23]$. Çalışmamızda ektopik gebeliklerin büyük çoğunluğunun $(\% 84,3)$ tubal ampuller yerleşimli oldukları saptanmıştır.

Ektopik gebelik olgularının en sık başvuru nedenleri pelvik ağrı, vajinal kanama, ve amenoredir. Farklı çalışmalardan elde edilen sonuçlarda, pelvik ağrı olguların \%67,598,6'inde, vajinal kanama \%45,2-56,4'inde gözlenmekte iken, amenore olguların yaklaşık $\% 75$ 'inde rapor edilmiştir [24-25]. Bizim olgularımızda pelvik ağrı \%95,3, pelvik ağrı ve amenore $(54,6)$, pelvik ağrı ve vajinal kanama $(40,6)$, yalnızca vajinal kanama $\% 4,6$ olarak tespit edildi. Yalnızca amenore şikayetiyle başvuran olmadı. Bu şikayetlerle gelen hastadan istenen $\beta$-HCG değerlendirmesi ve yapılan TVUSG ile tanıya varılmaktadır. Bizim çalışmamızda da başvuru esnasında alınan $\beta$-HCG değerlerinin hastaların $\% 53,1$ 'inde 5-1500IU/L olduğu ve TVUSG yapılan olguların \%96,8'inde ektopik gebeliği düşündürecek bulgular olduğu görülmüştür. Bu bulgulara dayanarak anamnez, $\beta$ HCG ve TVUSG üçlüsünün tanıdaki yerinin ne kadar önemli olduğunu görebiliriz [26]. Ektopik gebeliğin mevsimlere göre dağılımı incelendiğinde, olgularımızın \%35,9'unun sonbahar mevsiminde görüldüğünü tespit ettik ancak diğer mevsimlerle arasında anlamlı farklılık yoktu. Strolego ve ark. [27] ile Michelas ve ark. [28] yaptıkları araştırmalarda ektopik gebeliğin yaz döneminde daha fazla görüldügünü tesbit etmişlerdir. Bunların aksine, bazı araştırmalarda, ektopik gebeliğin özellikle kış ve bahar aylarında daha fazla görüldüğü saptanırken [29, 30], Romer ve ark. [31], ektopik gebeliğin görülme sıklığı açısından mevsimler arasında herhangi bir farklılık olmadığını savunmuşlardır. Bizim çalışmamızın sonuçları da bu çalışmaya paralel sonuçlar göstermektedir.

Ektopik gebeliklerin tedavisinde en sık kullanılan yöntem cerrahi yaklaşımlardır. Hemodinamik açıdan stabil ve fertilite isteği olan hastalarda ise laparoskopik yaklaşım en s1k tercih edilen cerrahi yöntemdir. Yao ve ark. [11] ektopik gebeliğin cerrahi tedavisinde laparoskopi ve laparotominin karşılaştırıldığ 1 çalışmalarında etkinliklerinin birbirlerine benzer olduğunu öne sürmüşlerdir. Salpingostomi yönteminin temel dezavantaj1, bu tedavi sonrasında persiste veya rekürren ektopik gebeliklerin gelişebileceğidir. Bizim çalışmamızda $34(53,1)$ hastaya laparotomi, $30(46,9)$ hastaya laparoskopi yapılmıştır. Yapılan operasyonlar sirasiyla \%62,5 salpenjektomi, \%29,7 salpingostomi, \%3,1 parsiyel ooferektomi, \%1,6 ooferektomidir. İki $(\% 3,1)$ hastada ise tubal abort olduğu tesbit edilmiştir.

Tedavi seçiminde hastanın fertilite beklentisi ile birlikte geçmiş hikayesi ve kontralateral tubanın durumu da büyük önem taşır. Dubuisson ve ark. [32] salpenjektomi uyguladıkları hastalarda daha önce tubal cerrahi geçirmemiş ve kontralateral tüpü normal olanlardaki intrauterin gebelik oranlarını \%75 olarak bildirmişler, geçirilmiş tubal cerrahi öyküsü olanlarda ise aynı oran \%36,6 olarak bildirilmiştir. Sonuç olarak salpenjektomi kontralateral tüpü normal olan olgularda oluşacak intrauterin gebelik oranlarını olumsuz etkilemezken, opere tüpte gelişebilecek persiste veya rekürren ektopik gebelikten korunma sağlayacaktır. Bizim kliniğimizde de salpenjektomi \%62,5 oranında ilk tercih edilen cerrahi yöntem olmuştur. Ayrıca hemodinamik olarak stabil olmayan ve kan transfüzyonu gerektiren hastalarda da salpenjektomi tercih edilmiştir. 
Sonuç olarak beş yıllık arşiv bilgilerimizden, kliniğimizde anamnez, $\beta$-HCG ve TVUSG ile ektopik gebelik ön tanısı almış olan olgularda öncelikle cerrahi yaklaşımı tercih ettiğimiz ortaya çıkmıştır. Güncel literatür bilgileri ışı̆̆ında, tubal hasarlı, hemodinamik olarak instabil olgularda persistans ve nükslerin önlenmesine yönelik laparoskopik salpenjektomi yönteminin öncelikle tercih edilmesi gereken cerrahi yaklaşım olduğu sonucuna ulaştık.

\section{Kaynaklar}

1. Farquhar CM. Ectopic pregnancy. Lancet 2005; 366: 583-91.

2. Thonneau P, Hijazi Y, Goyaux N, Calvez T, Keita N. Ectopic pregnancy in Conakry, Guinea. Bull World Health Organ 2002; 80: 365-70.

3. Condous G. Ectopic pregnancy: challenging accepted management strategies. Aust N Z J Obstet Gynaecol.2009; 49: 346-51.

4. Göktolga Ü. Ektopik Gebelik. Turkiye Klinikleri J Surg MedSci 2006; 2: 612.

5. Kirk E, Bourne T. The nonsurgical management of ectopic pregnancy. Curr Opin Obstet Gynecol 2006; 18: 587-93.

6. Cagnacci A, Landi S, Volpe A. Rhythmic variation in the rate of ectopic pregnancy throughout the year. AmJ Obstet Gynecol 1999; 180: 1067-71.

7. Buckley RG, King KJ, Disney JD, Gorman JD, Klausen JH. History and physical examination to estimate the risk of ectopic pregnancy: Validation of a clinical prediction model. Ann Emerg Med 1999; 34: 589-94.

8. Dart RG, Kaplan B, Varaklis K. Predictive value of history and physical examination in patients with suspected ectopic pregnancy. Ann Emerg Med 1999; 33: 283-90.

9. Lundorff P, Hahlin M, Källfelt B, Thorburn J, Lindblom B. Adhesion formation after laparoscopic surgery in tubal pregnancy: A randomized trial versus laparotomy. Fertil Steril 1991; 55: 911-5.

10. Lundorff P, Thorburn J, Hahlin M, Källfelt B, Lindblom B. Laparoscopic surgery in ectopic pregnancy. A randomized trial versus laparotomy. Acta Obstet Gynecol Scand 1991; 70: 343-8.

11. Yao M, Tulandi T. Current status of surgical and nonsurgical management of ectopic pregnancy. Fertil Steril 1997; 67: 421-33.

12. Bouyer J, Coste J, Shojaei T, Pouly JL, Fernandez H, Gerbaud L, Job-Spira N. Risk factors for ectopic pregnancy: A comprehensive analysis based on a large case-control, population-based study in France. Am J Epidemiol 2003; 157: $185-94$.

13. Storeide O, Veholmen M, Eide M, Bergsjø P, Sandvei R. The incidence of ectopic pregnancy in Hordaland County, Norway 1976-1993. Acta Obstet Gynecol Scand 1997; 76: 345-9.

14. Tancer ML, Delke I, Veridiano NP. A fifteen year experience with ectopic pregnancy. Surg Gynecol Obstet 1981; 152: 179-82.

15. Job-Spira N, Coste J, Aublet-Cuvelier B, Germain E, Fernandez H, Bouyer J, Pouly JL. Incidence of extra-uterine pregnancy and characteristics of treated patients. First results of the auvergne registry. Presse Med 1995; 24: 351-5.

16. Randic L, Haller H. Ectopic pregnancy among past IUD users. Int J Gynaecol Obstet 1992; 38: 299-304.

17. Doyle MB, DeCherney AH, Diamond MP. Epidemiology and etiology of ectopic pregnancy. Obstet Gynecol Clin North Am 1991; 18: 1-17.

18. Şahin HG, Zeteroğlu Ş. Sürücü R, Sucaklı MH, Kamacı M. Ektopik gebeliklerde risk faktörleri ve tanıyöntemlerinin değerlendirilmesi. Medical Network Klinik Bilimler ve Doktor. 2004; 10: 696-700.

19. Pradhan P, Thapamagar SB, Maskey S. A profile of ectopic pregnancy at Nepal medical college teaching hospital. Nepal Med Coll J 2006; 8: 238-42.

20. Coste J, Job-Spira N, Fernandez H, Papiernik E, Spira A. Risk factors for 
ectopic pregnancy: A case-control study in France, with special focus on infectious factors. Am J Epidemiol 1991; 133: 839-49.

21. Tharaux-Deneux C, Bouyer J, Job-Spira N, Coste J, Spira A. Risk of ectopic pregnancy and previous induced abortion. Am J Public Health 1998; 88: 4015.

22. Ankum WM, Mol BW, Van der Veen F, Bossuyt PM. Risk factors for ectopic pregnancy: a meta-analysis. Fertil Steril 1996; 65: 1093-9.

23. Bouyer J, Coste J, Fernandez H, Pouly JL, Job-Spira N. Sites of ectopic pregnancy: A 10 year population-based study of 1800 cases. Hum Reprod 2002; 17: 3224-30.

24. Alsuleiman SA, Grimes EM. Ectopic pregnancy: A review of 147 cases. J Reprod Med 1982; 27: 101-6.

25. Turhan NÖ, İnegöl İ, Seçkin NC. A three-year audit of the management of ectopic pregnancy. J Turkish German Gynecol Assoc 2004; 5: 310-3.

26. Agdi M, Tulandi T. Surgical treatment of ectopic pregnancy. Best Pract Res Clin Obstet Gynaecol 2009; 519-27.

27. Strolego F, Rustico M, Pregazzi R. Seasonal incidence of extrauterine pregnancy. Minerva Ginecol 1995; 47: 499-502.

28. Michelas S, Creatsas G, Fakas G, Kaskarelis D. Ectopic pregnancy: outcome of 152 cases. Int Surg 1980; 65: 355-8.

29. Coste J, Job-Spira N, Aublet-Cuvelier B, Germain E, Glowaczower E, Fernandez H, Pouly JL. Incidence of ectopic pregnancy. First results of a population-based register in France. Hum Reprod 1994; 9: 742-5.

30. Goldenberg M, Bider D, Seidman DS, Lipitz S, Mashiach S, Oelsner G. Seasonal patterns in tubal pregnancy. Gynecol Obstet Invest 1993; 35: 14951.

31. Römer T, Schmidt T, Negwer U, Rösel HD, Lober R. Is there a seasonal incidence of ectopic pregnancy?--A retrospective analysis. Zentralbl Gynakol 1994; 116: 628-30.

32. Dubuisson JB, Morice P, Chapron C, De Gayffier A, Mouelhi T. Salpingectomy - the laparoscopic surgical choice for ectopic pregnancy. Hum Reprod 1996; 11: 1199-203. 